\title{
HISTOPATHOLOGICAL INVESTIGATION OF BLASTOMYCOSIS IN ANIMALS AT DHAKA ZOO
}

\author{
S. A.Ahasan ${ }^{1,2 *}$, E. H. Chowdhury ${ }^{1}$, M. A. H. $\operatorname{Khan}^{1}$, R. Parvin ${ }^{1,3}$, S. U. Azam ${ }^{2,4}$, J. A. Begum ${ }^{1}$, \\ G.Mohiuddin $^{2}$, J. Uddin', M. M. Rahman ${ }^{2}$ and M. A. Rahman ${ }^{2}$ \\ ${ }^{1}$ Department of Pathology, Faculty of Veterinary Science, Bangladesh Agricultural University, \\ Mymensingh-2202, Bangladesh \\ ${ }^{2}$ Department of Livestock Services, Bangladesh; KrishiKhamarSarak, Farmgate, Dhaka-1215, Bangladesh; \\ ${ }^{3}$ Institute of Virology, Faculty of Veterinary Medicine, University of Leipzig, An den Tierkliniken 29, 04103 \\ Leipzig, Germany \\ ${ }^{4}$ Monash University, Gippsland Campus, Victoria-3842, Australia
}

\begin{abstract}
Dhaka Zoo with 2000 animal heads of 184 species from significant genetic diversity and five million visitors' influx round the year is placing it a public health important spot. This study was conducted to investigate blastomycosis in animals at Dhaka Zoo to ascertain animal health, welfare and public health safety standard. One hundred and two necropsied tissue samples preserved in $10 \%$ neutral buffered formalin at necropsy from 36 animals of 25 different species were collected from Dhaka Zoo. Twenty five out of 36 study animals were suffering from granulomatous diseases. Among them three animals were found suffering from blastomycosis. Clinical history, nodular lesions from necropsy findings, granulomatous reactions with fungal spores on histopathology and spherical yeast cells with double contoured wall and broad base budding on special staining were used for the confirmation of blastomycosis in spotted deer (Cervus axis/Axis axis), nilgai (Boselaphustragocamelus) and horse (Equuscaballus).Present study provides evidence of existing blastomyosis and similar long standing zoonotic diseases in majority of rest of the animals with health risk that shades health safety standard at Dhaka Zoo.
\end{abstract}

Key words:Blastomycosis, Granulomatous, Health safety, Dhaka zoo.

\section{INTRODUCTION}

Zoo is popularly called living laboratory and knowledge generation center for wildlife implying both insitu and ex-situ (WAZA, 2005; Ahasan andAzam, 2007). Genetic, species, subspecies and population diversity shaped zoos an environmental hot spot and sourcing of disease producing microorganismsand predispose cross infection of closely related animals. Around 150 emerging and re-emerging infectious diseases are originating from or harbored in wildlife round the globe (OIE, 2000; Lisle et al., 2002) while600 million visitorinfluxes each year in zoos of the whole planet (Dollinger, 2006). Considering the biological diverse range of wildlife, multiple disease susceptibility and huge visitor influx confirms zoos as an important and obligated public health concern arena (O'Reilly and Daborn, 1995; OIE, 2000; Tribe, 2004; WAZA, 2005). Among others, bacterial and fungal diseases are most prevailing infections in zoo collections. The worst infectious diseases considered are mycobacteriosis and mycosis; both the groups posesses seriously zoonotic, curving the animal welfare and public health standard (WAZA, 2003) of zoos in calling it modern zoo. Even then, zoos are inseparable from studying biodiversity and environment, public health and knowledge generation center (WAZA, 2005) for mankind. It is also limited with different social conflicts, health-hazards, management, behavioral menace and so forth (Salem and Rowan, 2001).

Since its inception, zoo is a potential source of plague, tuberculosis, herpes virus B (hepatitis), rabies, Marburg virus, fungus and parasitic worm among others (Renquistand Whitney, 1978; Gary et al., 2003). A recent threat has come up with West Nile and hanta viruses (Gary et al., 2003). Dhaka zoo has a prevalence of mycobacteriosis, salmonellosis, colibacillosis, coccidioidomycosisand those are diagnosed only on the basis of clinical history and necropsy records (Rahman and Ahasan, 2006 and 2007).

Blastomycosis is a systemic infection caused by Blastomyces dermatitidis, a dimorphic fungus. The organism exists as yeast in tissues at body temperature. These organisms have a thick, refractile, double capsule and shows broad-base budding. Human and dogs are the most frequently infected species, however, the infection can also be found in cats, horses, ferrets, wolves, deer, polar bear, African lion, Atlantic bottle nose dolphin, Stellar's sea lion and bats (Richard, 1987; Raymond et al., 1997; Marcel et al., 2000).

*Corresponding e-mail address: ahasan67@gmail.com 
However, these diseases were not investigated in Dhaka zoo except apprehension from necropsy findings. Therefore, the present study was undertaken to investigate the prevalence of blastomycosis and to investigate the clinico-pathological changes of blastomycosisin animals at Dhaka Zoo to apprehend public health safety standard prevailed here.

\section{MATERIALS AND METHODS}

The research work was conducted in the Department of Pathology, Bangladesh Agricultural University (BAU), Mymensingh-2202 and Dhaka Zoo, Bangladesh. A total of 102 necropsied formalin-fixed tissue specimens from 36 animals of 25 different species at necropsy from Dhaka Zoo captivity were investigated clinico-histopathologically and special staining. The study comprised of eight rhesus macaques (Macacamulatta), four spotted deers (Cervus axis/Axis axis), two samberdeers (Cervus unicolor), two golden pheasant (Chrysolophuspictus), while guineapig (Caviaporcellus), wildebeest (Connochaetestaurinus), striped hyena (Hyena hyena), Indian/Asiatic lion (Pantheraleopersica), gayal (Bosfrontalis), American rhea (Rhea americana), Australian terrier dog (Canis lupus familiarizes), zebra (Equus zebra hartmannae), nilgai (Boselaphustragocamelus), horse (Equuscaballus), barking deer (Muntiacusmuntjak), ostrich (Struthiocamelus), crested serpent-eagle (Spilorinscheela), common languor (Presbytis entellus), fishing cat (Felisviverrina), beisaoryx (Oryx beisabeisa), reticulated python (Python molurus), water buck (Kobus L. leche), greater kudu (Tragelaphusstrepsiceros), and olive baboon (Papioanubis) were each single sampled animals. The animal belongs to non-human primates $(n=10)$, carnivores $(n=4)$, herbivores $(n=16)$, reptiles $(\mathrm{n}=1)$ and birds $(\mathrm{n}=5)$ groups.

At necropsy, tissue changes were recorded; photographed and lesioned tissues of all vital organs with special attention to nodular lesions were preserved in $10 \%$ neutral buffered formalin. Formalin fixed samples were processed for paraffin embedding, sectioning and staining as routine hematoxylin and eosin staining (Luna, 1968), periodic acid Schiff (PAS) for fungus according to standard method of histopathological study (Mallory, 1968).

Photomicrograph was taken at the Department of Pathology and Field Fertility Clinic of the Department of Surgery and Obstetrics, Bangladesh Agricultural University, using photomicrographic camera (Olympus PM-C 35 Model) and Digital Camera Mounted Photomicrographic device (Diffrential Interference Contrast - DIC) (Olympus, Nizol FC, E-5000, 8.4V, 0.9A, CE N 150) respectively.

\section{RESULTS AND DISCUSSION}

Twenty five out of 36 investigated animals were found suffering from granulomatous diseases (about 70\%) (Graph 1) whilethree animals (spotted deer: Cervus axis/Axis axis,nilgai:Boselaphustragocamelusand horse:Equuscaballus) were found suffering from blastomycosis.Clinically, the affected animals showedvery frequent anorexia and coughing, progressive emaciation and weakness followed by death. Necropsy unearthed findings of tiny white minute to larger nodulations, cavitations, caseations, and suppurations and blackish to greenish discolorations of the organs (Figure 1 to 4).Routine histopathology depicted typical granulomatous reactions (Figure5, 6).Multifocal to diffuse and severe form of granuloma with formation of bothLanghang's and foreign body giant cells (Figure6)were recoded along with fungal spores. Limited calcification and with or without encapsulation (Figs. 5 and 6) were also noted. Blastomyces organisms as spherical, yeast like cells with double contoured walls, refractile body as a central mass, budding and limited encapsulation was identified by PAS in all the affected organs but very often in lung, liver, spleen and intestine (Figure 7, 8).

Clinical history noted in this study was almost similar to other works without unnoticeable degree of variations; blastomycosis and mycobacteriosis were difficult to differentiate, nonetheless. Frequently observed clinical signs were coughing, anorexia and emaciation occasional weakness followed by death of affected animals in this study were comparable to study conducted by Lisle et al. (2002). Yellow white tiny to large nodules on visceral organs at necropsy was typical to findings of other researches (Lisle et al., 2002). Infrequently, non-correspondance to granulomatous reaction with nodular lesions was observed.

Most literature suggests the presence of foreign body giant cells in case of mycosis with the exception of findings by Jones et al. (1997) that suggests formation of both Langhan's and foreign body giant cells in case of blastomycosis while present investigation showed presence of both type of giant cells with huge number of Langhan's type giant cells than foreign body.

The disease in nilgai and horse as found in the work was not compared due to information insufficiency. It is termed as the principal systemic mycosis of humans and animals worldwide (Marcel et al., 2000). On histopathology, lesions were recorded in majority of cases as granuloma with the formation of Langhan's cells and occasional foreign body giant cells without fibrous encapsulation but limited calcification having a good agreement with Jones et al., (1997) 


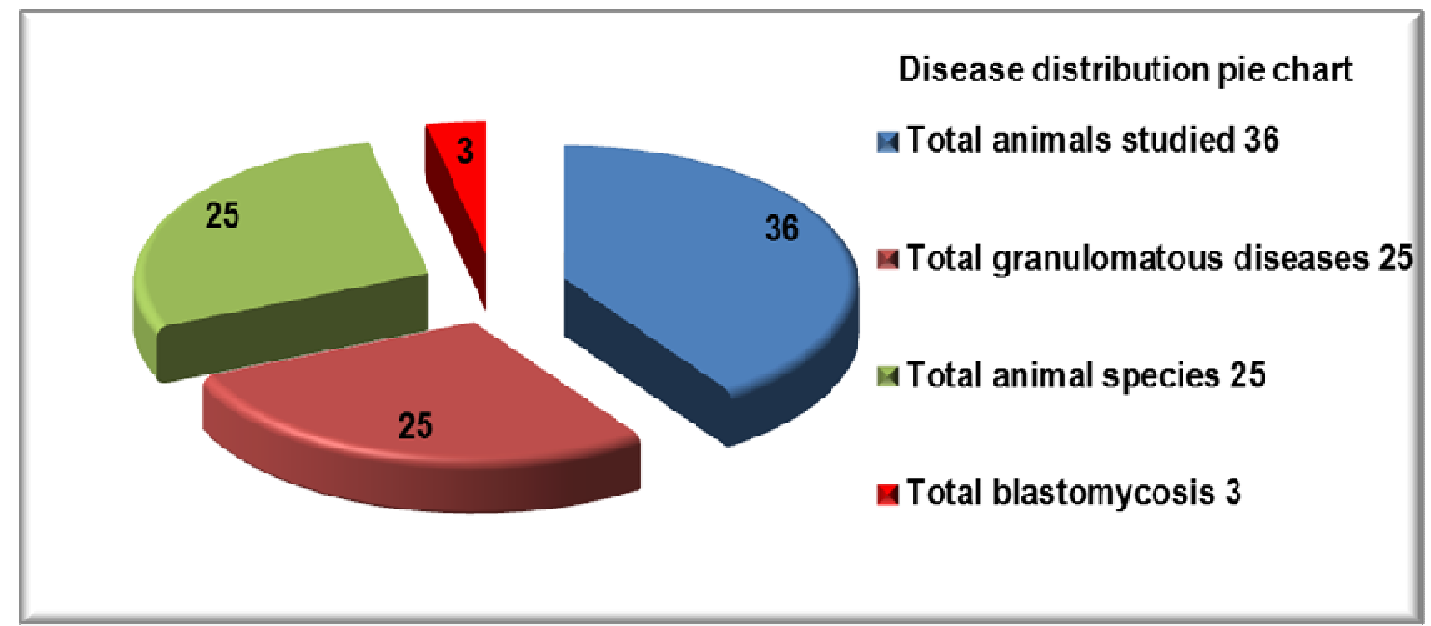

Graph 1: Distribution of diseases in animals studied
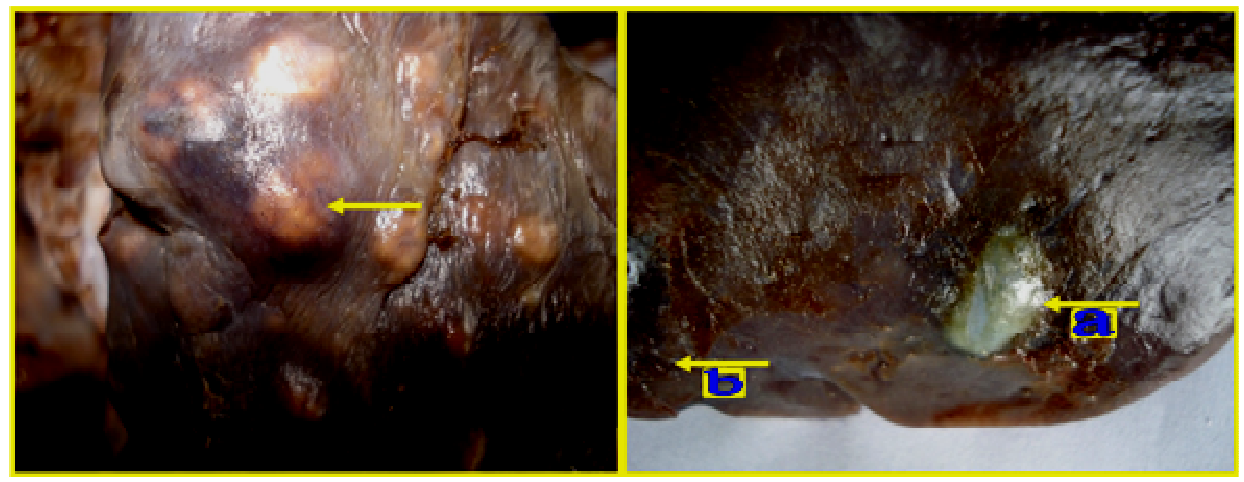

Fig. 1: Lung of spotted deer,

Fig. 2: Liver of spotted deer, a large numerous caseous nodules, blackish abscess (a) and numerous tiny nodules discoloration (b), greenish to brownish discoloration
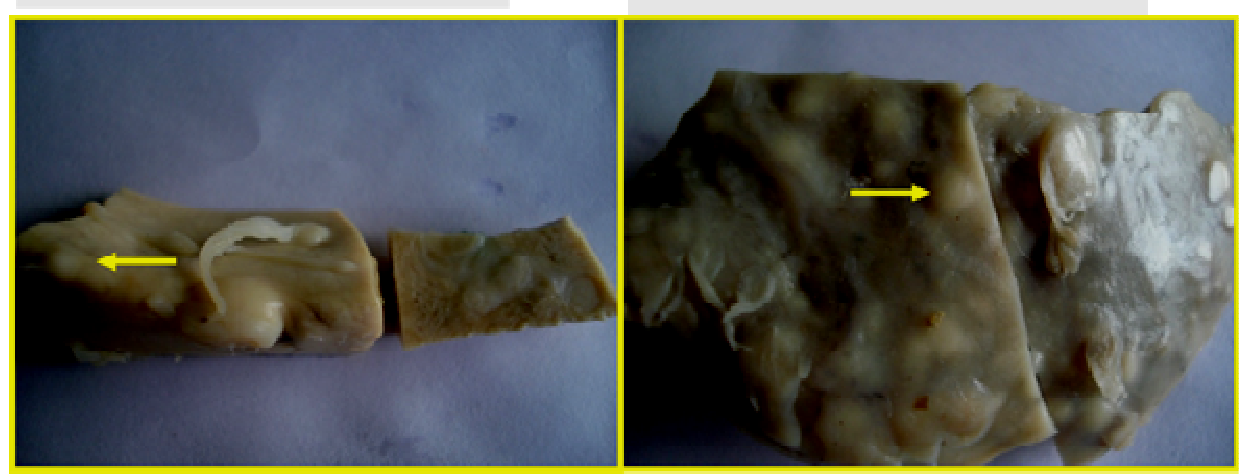

Fig. 3: Liver of Nilgai, nodulated

Fig. 4: Lung of Nilgai, numerous caseous nodules 


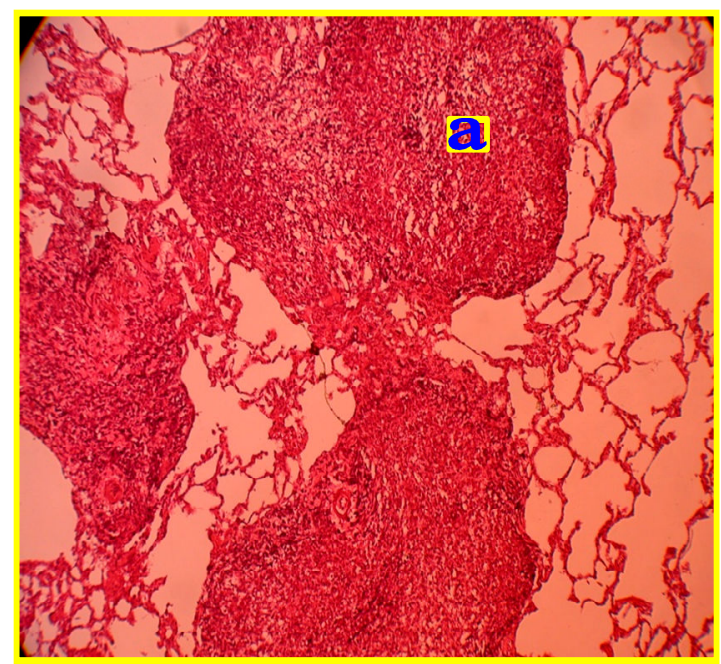

Fig. 5: Lung of spotted deer, granuloma (a) and formation of giant cells, multifiocal, severe granulomatous pneumonia, $\mathrm{H} \& \mathrm{E}, \times 82.5$

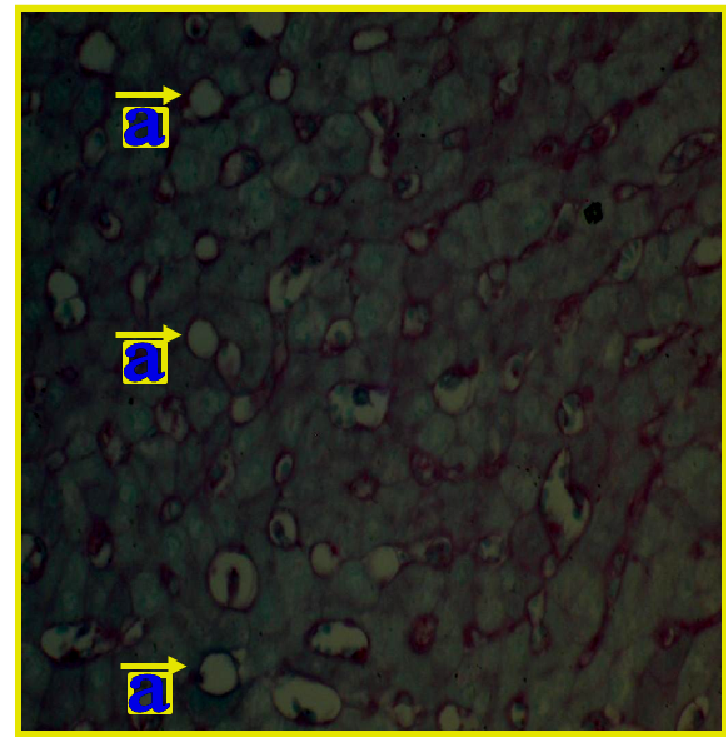

Fig. 7: Liver of Nilgai, spherical yeast cells with Fig. 8: Liver of spotted deer, organisms as double contoured wall and with budding (a), spherical, yeastlike cells with double contoured diffuse, severe mycotic hepatitis, Blastomycosis, PAS, $\times \mathbf{4 0 0}$

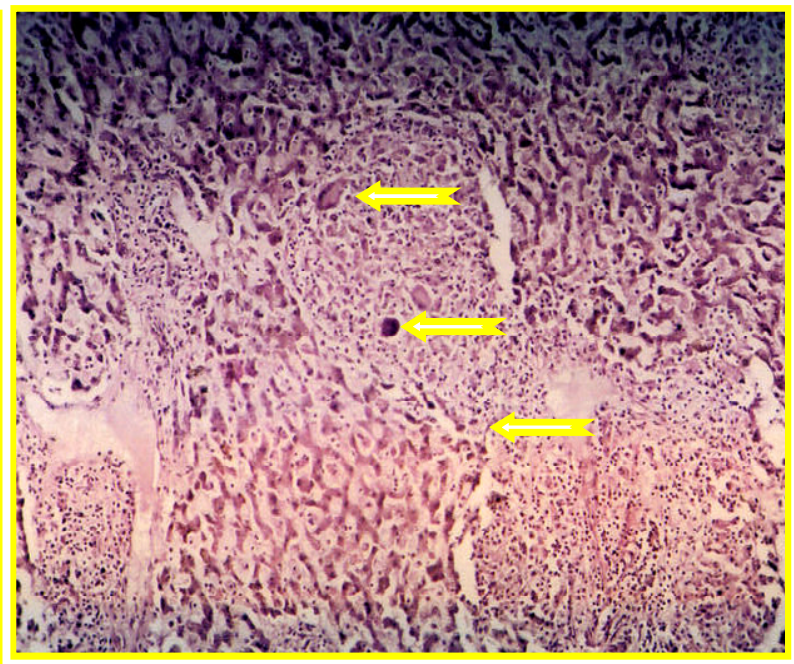

Fig. 6: Liver of nilgai, formation of granuloma and huge number of giant cells, fungal spores, multifocal, severe, granulomatous mycotic hepatitis, H\&E, $\times 82.5$.

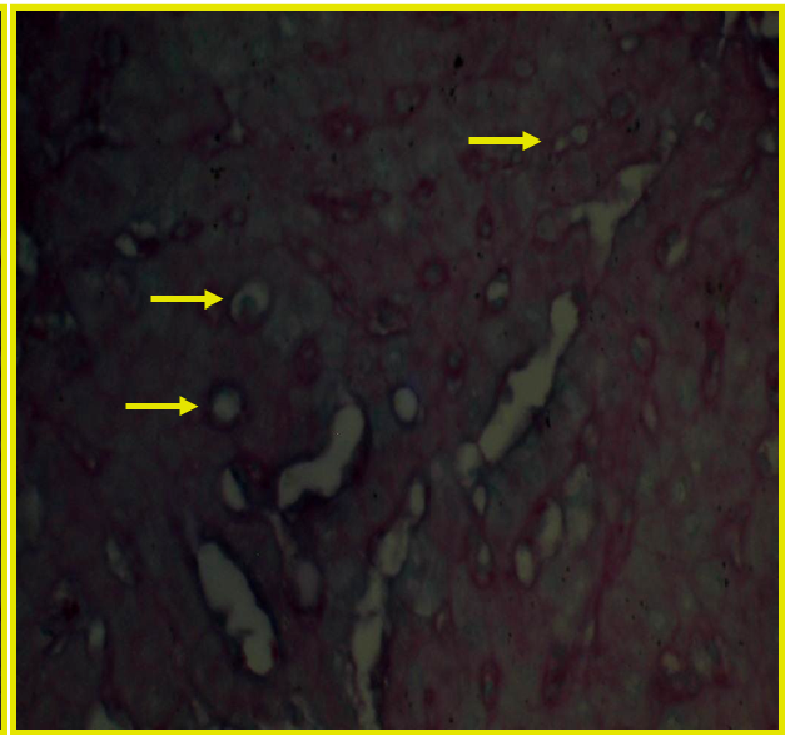
walls, retractile body as a central mass and have limited encapsulation, blastomycosis, PAS, $\times 400$ 


\section{CONCLUSION}

Dhaka zoo could possess this organism through dusty aerosol, contaminated food, animal importation that is infected or immune compromised or malnourished. However, further studies should be focused on typing and molecular characterization of Blastomyces organisms. Blastomycosis possesses serious public health consequences and therefore, prevention and control of the disease in Dhaka Zoo should brought under notice to ensure health safety standard.

\section{REFERENCES}

1. Ahasan SA and Azam SU (2007). Contribution of Zoological Gardens towards conservation of Wildlife and Biodiversity - Bangladesh perspective. Zoos' print 22: 13-16.

2. Dollinger P (2006). Marketing the conservation role of zoos' and aquariums. Zoos' Print 21:17.

3. Gary Witmer, Thomas De Liberto, Kurt, VerCauteren and Peter Butchko (2003). Mycobacterial diseases in wildlife; wildlife damage management, Internet center for USDA National Wildlife Research Center, Staff Publication, University of Nebraska, Lincon.

4. Raymond JT, White MR, Kilbane TP and Janovitz E B (1997). Pulmonary blastomycosis in an Indian fruit bat (Pteropusgiganteus). Journal of Veterinary Diagnostic Investigation 9(1), 85-87.

5. Jones TC, Hunt RD \& King NW (1997). Diseases caused by fungi in Veterinary Pathology, $6^{\text {th }}$ edn., Williams and Wilkins, 8:506-522.

6. Zwick LS, Briggs MB, Tunev SS, Lichtensteiger CA and MurnaneRD (2000). Disseminated blastomycosis in two California sea lions (Zalophuscalifornianus). Journal of Zoo and Wildlife Medicine 31(2): 211-214.

7. Lisle De GW, Bengis RG, Schmitt SM and O'Brien DJ (2002). Tuberculosis in freeranging wildlife: detection, diagnosis and management. Revue Scientifique at Technique des Office International des Epizooties. 21:317-334.

8. Luna L (1968). Manual of histologic staining methods of the Armed Forces Institute of Pathology. New York.

9. Mallory FB (1968). Pathological Technique, New York, Hafner Publishing Co. 275. AFIP modification.

10. Marcel W, Hanna IF and Bruce SK (2000). Mutation of the WI- 1 gene yields an attenuated Blastomycesdermatitidis strain that induces host resistance, Journal of clinical Investigation106: 13811389.

11. Varani N, Baumgardner DJ, Czuprynski CJ and Paretsky DP (2009). Attempted isolation of Blastomycesdermatitidis from the nares of dogs: northern Wisconsin, USA. Medical Mycology 47 (7): 780-782.

12. Office International des Epizootic (OIE) (2000). Zoonoses transmissible from non-human primates. Chapter 2.10.1. In: International animal health code, 9th Ed. OIF, Paris. 285-290.

13. O'Reilly LM and Daborn CJ (1995). The epidemiology of Mycobacterium bovis infections in animals and man. Tubercle and Lung Disease (Supplement 1) 76: 1-46.

14. Rahaman AZ and Ahasan SA (2007). Mortality in Dhaka Zoo due to microbial agents. Bangladesh Journal of Microbiology, 24:154-156.

15. Rahman AZ and Ahasan SA (2006). Spotted deer (Cervus axis) herd in Dhaka Zoo: case report. Zoos' Print Magazine 21.

16. Renquist DM and Whitney RA (1978). Tuberculosis in non-human primates - an overview. In Proc. Symposium on mycobacterial infections in zoo animals (R.J. Montali, ed.), 6-8 October 1976, Front Royal, Virginia. Smithsonian Institution Press, Washington, DC. 9-16.

17. Richard PT (1987). Blastomycosis in Wild Wolves. Journal of Wildlife Diseases 23: 321-323.

18. Salem DJ and Rowan AN (2001). The State of the Animals: Humane Society Press, Gaithersburg, Maryland.

19. Tribe A (2004). Zoo Tourism, In: Wildlife Tourism: Impacts, management and planning.Higginbottom, Karen (ed.), Common Ground Publishing, Altona, Victoria. 35-56.

20. Brandhorst TT, Wüthrich M, Warner T and Klein B (1999). Targeted gene disruption reveals an adhesin indispensable for pathogenicity of Blastomycesdermatitidis. The Journal of Experimental Medicine 189(8): 1207-1216.

21. WAZA (2003). Code of ethics and animal welfare, proceedings of the $58^{\text {th }}$ annual meeting. San Joe's, WAZA executive Office, Berne. 139-142.

22. WAZA (2005). Building a future for wildlife. The World Zoo and Aquarium Conservation Strategy. 74. 